GABA Agonists could Decrease Hyperalgesia and NO Serum Level in Morphine Tolerance Model

Shima Mehrabadi and Seyed Shahabeddin Sadr

\title{
International Journal of Advanced Biological and Biomedical Research
}

Journal DOI: $10.18869 / \mathrm{IJABBR}$

ISSN: $2322-4827$

CODEN (USA): IJABIS

http://ijabbr.com
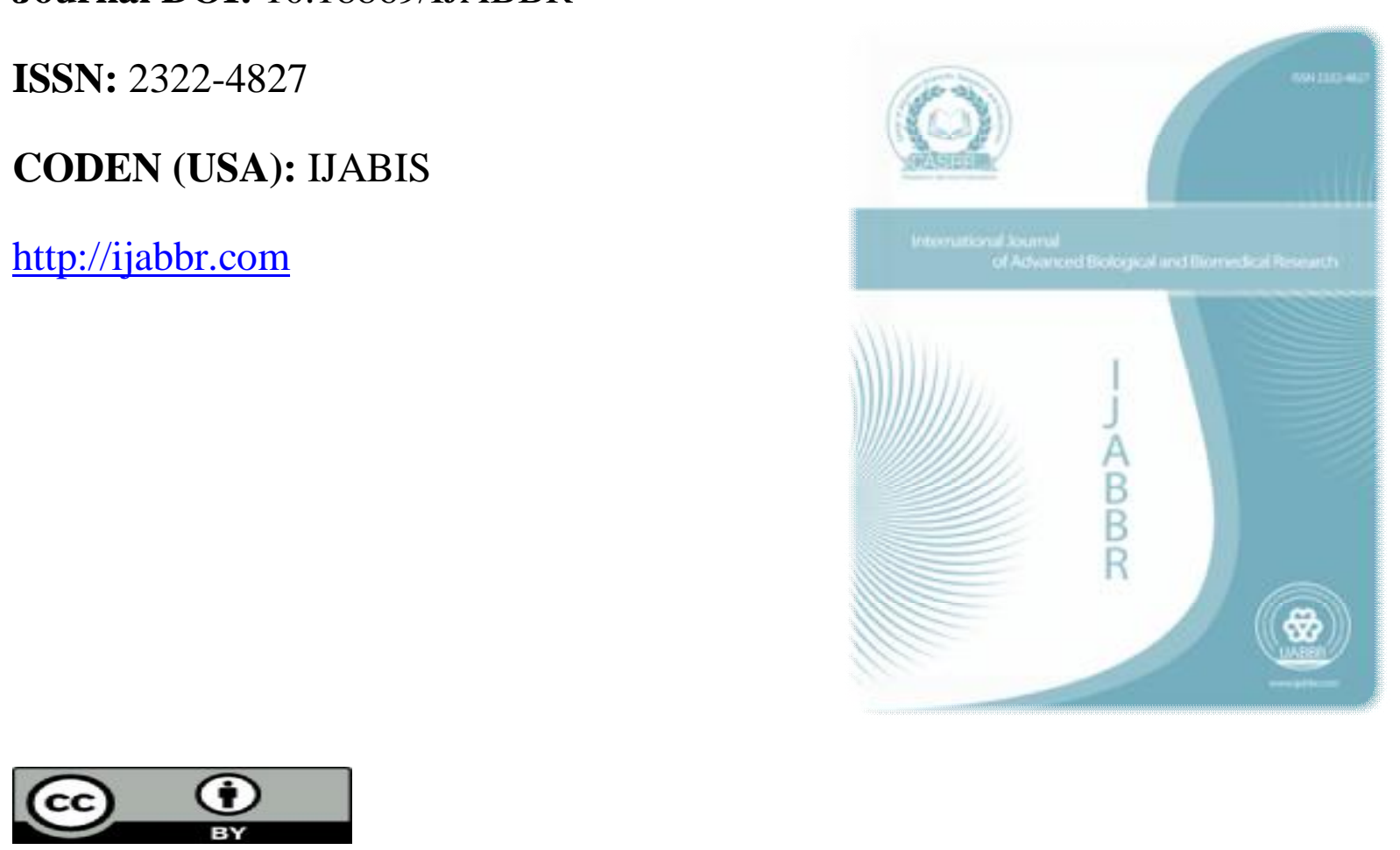

Copyright $@ 2018$ by authors and the Sami Publishing Corporation(SPC). This work is licensed under the Creative Commons Attribution International License (CC BY4.0).

https://creativecommons.org/licenses/by/4.0/ 


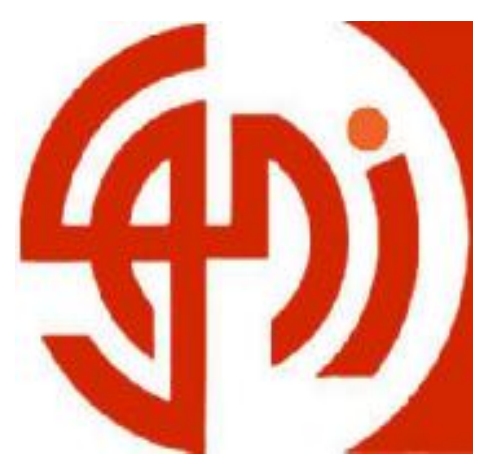

Available online at http://ijabbr.com

International Journal of Advanced

Biological and Biomedical Research

6(2) (2018) 129- 134

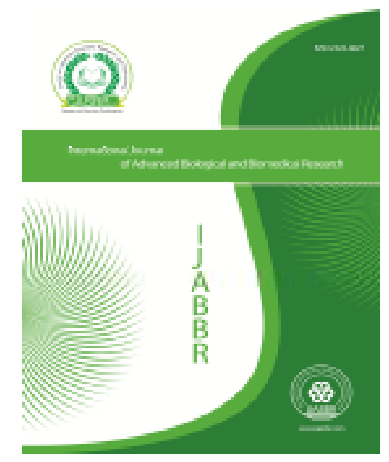

Original Article

Open Access

\title{
GABA Agonists could Decrease Hyperalgesia and NO Serum Level in Morphine Tolerance Model
}

\section{Shima Mehrabadi* and Seyed Shahabeddin Sadr}

Department of Physiology, School of M edicine, Tehran University of M edical Sciences, Tehran, Iran.

\begin{abstract}
Several studies have demonstrated that nitric oxide (NO) is involved in hyperalgesia induced by NMDA activity in Morphine tolerance and NO synthase inhibitors can attenuate hyperalgesia in morphine tolerance. In addition, one of the possible mechanisms in morphine tolerance is reduction of GABA inhibitory effect. For this reason, we used GABA agonists (muscimol and baclofen) to investigate the effect of GABA agonists on analgesic effect of morphine and NO level of serum. In this study, experimental rats were divided into 4 groups as follows: 1. Control group, 2. Morphine tolerance group, 3. Morphine tolerance + muscimol, and 4-morphine tolerance + baclofen. To induce morphine tolerance in rats, the animals received $10 \mathrm{mg} / \mathrm{kg}$ of morphine sulfate intraperitoneal (ip) once a day for 8 days. In the treatment group, GABA agonist was injected on the $1^{\text {st }}, 3^{\text {rd }}, 5^{\text {th }}$, and $8^{\text {th }}$ day before morphine injection. Finally, to evaluate GABA agonists treatment on morphine analgesia and hyperalgesia on the $8^{\text {th }}$ day of the study, thermal hyperalgesia was used to evaluate tolerance and hyperalgesia. Then, NO level of serum was investigated as an important factor in $\mathrm{OlH}$. The results indicated that GABA agonists reduced thermal hyperalgesia in the morphine tolerance group $(p<0.05)$. Furthermore, in the morphine tolerance group, NO significantly increased in comparison to the control group $(p \varangle 0.01)$; however, after treatment with GABA agonists, NO decreased in the morphine tolerance group $(P \varangle 0.01)$. This study indicates that GABA agonists even under effective dose decreased the NO released by activation of NM DA and improved OIH.
\end{abstract}

(c) 2018 Published by CASRP Publishing Company Ltd. UK. Selection and/or peer-review under responsibility of Center of Advanced Scientific Research and Publications Ltd. UK.

Keywords: M orphine, GABA agonists, NO, Thermal hyperalgesia

\section{*Corresponding author: shimamehrabadi@yahoo.com}

(c) 2018 The Authors. This is an open access article under the terms of the Creative Commons Attribution-Non Commercial- No Derives License, which permits use and distribution in any medium, provided the original work is properly cited, the use is non-commercial and no modifications or adaptations are made. 
Shima M ehrabadi and Seyed Shahabeddin Sadr / International Journal of Advanced Biological and Biomedical Research (2018) 7(1) 129-134

\section{Introduction}

Chronic pain is an important problem affecting individuals' quality of life. Approximately 116 million Americans (about $30 \%$ of the population) suffer from chronic pain. The economic impact of chronic pain is extremely costly, reaching around $\$ 100$ billion annually (Renfrey et al., 2003). Recent studies have attempted to obtain the best results to treat chronic pain at a minimum cost. Nowadays, opioid drugs are the gold standard for the treatment of chronic pain (Bekhit, 2010). However, long-term use of these drugs is limited by the development of analgesic tolerance or dependence and hyperalgesia observed in both laboratory animals and patients (Rudd et al., 2016). Opioid induced hyperalgesia $(\mathrm{OIH})$ is a phenomenon observed in the patients treated with opioids, demonstrating an increased sensitivity to painful stimulus (Velayudhan et al., 2014). Nitric oxide is a free radical that, among other functions, behaves as an intracellular and intercellular messenger in the nervous system (Snyder, 1992). Several studies have indicated that NO is involved in the hyperalgesia induced by peripheral nerve injury (Meller et al., 1992). Nitric oxide system also participates in the development of opioid tolerance, withdrawal and hyperalgesia induced with morphine (Li and Clark, 2001). One of the methods considered today is co-administration of other drugs with morphine to reduce tolerance to anti-nociception effect and reduction of hyperalgesia in morphine tolerance state (M anning et al., 1996; Tiseo and Inturrisi, 1993). In addition, studies have shown that development of tolerance to the antinociceptive effects of morphine can be prevented by coadministration of morphine with GABA agonists such as gabapentin, baclofen and muscimol. Furthermore, these drugs in treatment dose are extensively used as analgesic drugs and reduce hyperalgesia in neuropathic pain (Gilron et al., 2005; Backonja and Glanzman, 2003; Idänpään-Heikkilä and Guilbaud, 1999; Hwang and Yaksh, 1997; Hosseini et al., 2014). Perhaps, one of the causes of reduction of the antinociceptive effect of morphine and inducing hyperalgesia in the long-term administration is changes of GABA inhibitory effect in supraspinal and spinal level in the central nervous system (CNS) (Ma and Pan, 2006; Bobeck et al., 2014; Takahashi and Kaneto, 1995). Findings indicated that pharmacological manipulations of the GABA system caused changes in morphine analgesia, tolerance and physical dependence (Ho et al., 1976; Hwang and Yaksh, 1997). In the present study, sub-effective dose of GABA agonists not inducing analgesic effect was used to investigate the co-administration effect of these two drugs on anti-nociceptive effect of morphine and NO level of serum inducing hyperalgesia in the long-term morphine administration.

\section{Materials and methods}

\subsection{Animals}

24 male Wistar rats weighing 180-200 g Rats used in this study. Animals were kept in their cages at room temperature $\left(21 \pm 2{ }^{\circ} \mathrm{C}\right)$ under a normal $12 \mathrm{hr}$ light: $12 \mathrm{hr}$ dark cycle with free access to food and water. The study was conducted in Shahid Beheshti University of Medical Science University. Rats were randomly allocated into 4 experimental groups, ( $n=6$ per group): 1 . Control group; received $1 \mathrm{ml}$ normal saline $(9 \% \mathrm{NaCl}), 2$. Morphine tolerance group: 8 days received morphine once in every day, 3. M orphine tolerance and muscimol as $\mathrm{GABA}_{\mathrm{A}}(0.5$ $\mathrm{mg} / \mathrm{kg}$; i.p.) and 4. Morphine tolerance and baclofen as GABAB agonist ( $0.5 \mathrm{mg} / \mathrm{kg}$; i.p.).

\subsection{Drug administration}

To induce tolerance to analgesic effects morphine hydrochloride (Temad, Iran) was administered chronically in a daily dose of $10 \mathrm{mg} / \mathrm{kg}$ i.p from days 1 to 8 (Hill et al., 2016). To determine the effect of GABA agonists on the development of morphine tolerance and hyperalgesia, muscimol (Sigma-Aldrich, USA) were used as GABAA agonist and baclofen (Zahravi CO, Iran) were used as GABAB agonist were administrated i.p at a dose of $0.5 \mathrm{mg} / \mathrm{kg}$ as under effective dose that determined in before our before study in $1,3,5,8$ days 30 min before injection of Morphine. Then, plantar test and Nitric oxide serum evaluation was performed $8^{\text {th }}$ days $20-30$ min after morphine injection. All drugs were dissolved in physiological saline

\subsection{Paw withdrawal test (thermal hyperalgesia)}

Paw withdrawal latency (PWL) from noxious heat was assessed using the plantar test (Ugo Basile, Verse, Italy). Rats were placed in Plexiglas boxes for 10 to 15 minutes before testing to habituate to the test environment in both experimental and control groups on the $8^{\text {th }}$. The infrared light was positioned under the plantar surface of 
the rats' hindpaws and projected focally. PWL was automatically recorded by a digital timer to the nearest $0.1 \mathrm{~s}$ connected to the heat source (infrared light). Heating was stopped at $20 \mathrm{~s}$ cut off to prevent tissue damage. PWLS were measured 3 times for left paw in all of rats at an interval of 5 minutes, and then the mean latency was computed (Fraser et al., 2000).

\subsection{Nitric oxide serum level}

The blood was collected in heparinized tubes used Griess's reaction. NO concentration was determined using an indirect method based on measuring nitrite concentration in serum according to Griess's reaction. In the samples analyzed, nitrate was reduced to nitrite in the presence of cadmium (Sigma-Aldrich, Steinheim, Germany), and then converted to nitric acid that gave a color reaction with Griess's reagent (Sigma-Aldrich, Stainheim, Germany). Nitrite concentrations were determined by spectrophotometric analysis at $540 \mathrm{~nm}$ with reference to a standard curve. NO products were expressed as $\mu$ moles (Ratajczak-Wrona et al., 2013).

\section{Results and discussion}

\subsection{Effect of GABA agonists on thermal hyperalgesia in morphine tolerance rats}

According to Fig. 1. paw withdrawal threshold decreased in the morphine tolerance group (mor) compared to the control group. One-way ANOVA followed by Tukey post-hoc test indicated that hyperalgesia significantly induced on the $8^{\text {th }}$ day in the morphine tolerance group compared to the vehicle group $(p<0.01)$. M oreover, GABA agonists under effective dose administration with morphine (muscimol and baclofen group) could attenuate hyperalgesia in the morphine tolerance group and increase paw withdrawal threshold $(p \varangle 0.05)$.

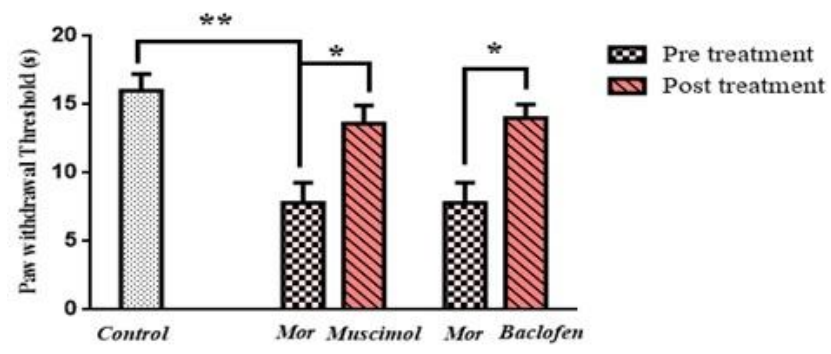

Fig. 1. Paw withdrawal threshold decreased in the morphine tolerance group (mor) compared to the control group.

\subsection{Determination of total NO concentration in serum}

Fig. 2. shows the levels of serum total concentration of NO in the control, morphine tolerance group (mor) and morphine tolerance group treated with GABA agonists (muscimol and baclofen). In the serum of the morphine tolerance group, NO significantly increased in comparison to the control group $(p \varangle 0.01)$. After treatment with GABA, agonists lower concentrations of total NO were observed in the morphine tolerance group treated with GABA agonists $(P \varangle 0.01)$ and improved serum NO concentration; perhaps for this reason, it could attenuate hyperalgesia in paw withdrawal threshold in the morphine tolerance group.

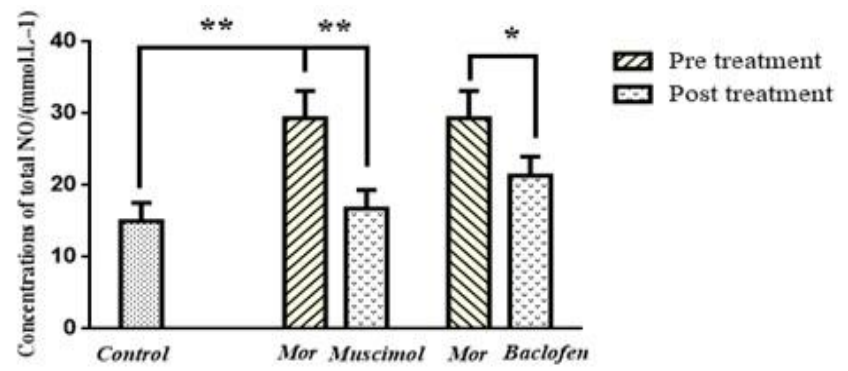

Fig. 2. The levels of serum total concentration of $\mathrm{NO}$ in the control, morphine tolerance group (mor) and morphine tolerance group treated with GABA agonists (muscimol and baclofen). 
In this study, it was observed that morphine tolerance could decrease paw withdrawal threshold (thermal hyperalgesia) and GABA agonist could prevent the induction of hyperalgesia in the long-term morphine administration. In addition, in another part of results, it was shown that GABA agonists reduced increased level of NO in morphine tolerate rats, indicating that GABA agonists (muscimol and baclofen) can increase antinociceptive effect of morphine and inhibit tolerance and hyperalgesia in long-term administration. Recent studies investigated the effect of many types of GABA agonists on the antinociception effect of morphine; however, some GABA agonists can induce analgesic alone (Ho et al., 1976; Sivam and Ho, 1983). In this study, under effective dose of GABA agonists that do not induce analgesic effect were used in rats, and it was discovered that GABA agonist even under effective treatment dose could improve morphine analgesia and inhibit hyperalgesia in long-term use. Local increase in cortical GABA concentration changed the nociceptive threshold by acting on the descending pain inhibitory system (Hunt and Mantyh, 2001). Similar to this study, other research showed that increase in GABA release in VTA during morphine withdrawal reduced morphine withdrawal symptoms and opioid induced hyperalgesia (OIH) (Bonci and Williams, 1997). Additionally, it was revealed that GABA agonists could attenuate tolerance and hyperalgesia through affecting spinal cord level in addition to affecting VTA in the brain. It was also revealed that possible mechanism of GABA in spinal cord level to decrease tolerance resulted from reduction of NO in the spinal cord. Nitric oxide is a free radical that, among other functions, behaves as an intracellular and intercellular messenger in the nervous system. It is synthesized by nitric oxide synthase, of which three isoforms have been characterized (Knott and Bossy-Wetzel, 2009). Studies indicated that NO concentration increased in serum in patients with hyperalgesia like neuropathic or cancer pain (Zanfirescu et al., 2017; M eller et al., 1992; Kolesnikov et al., 1993). Furthermore, in similar studies in opioid tolerance models, NO concentration also increased and induced hyperalgesia in the long-term use of opioids (Kolesnikov et al., 1993). Opioid-induced hyperalgesia $(\mathrm{OIH})$ is a state in which nociceptive is sensitized more than normal, which is caused by exposure to opioids. In fact, patients receiving opioids for the treatment of pain could become more sensitive to certain painful stimuli (Dumont et al., 2007). The precise cellular and molecular mechanism of OIH is not yet understood. Recent evidence has shown that activation of the $\mathrm{N}$-methyl-D-aspartate receptor mediates the thermal hyperalgesia produced in a model of neuropathic pain and OIH (Malmberg and Yaksh, 1993). Studies reported that N-methyl-Daspartate caused production of nitric oxide and activation of soluble guanylate cyclase and induce nociception (Quintero et al., 2011). Continuous production of nitric oxide and soluble guanylate cyclase in the lumbar spinal cord mediates the thermal hyperalgesia produced in neuropathic and OlH models in rats (Schmidtko et al., 2008). Hyperalgesia is initiated by a decreased and delayed GABA release and increases glutamate release and NMDA glutamate receptor activation at the spinal level, following increased NO release (Quintero et al., 2011). Indeed, deficient GABA release could increase in glutamate release above a normal physiological range, and GABA can be increased with GABA agonists to reduce GABA/glutamate imbalance and decrease NO release in managing hyperalgeisa induced by opioids in patients in long-term use of morphine.

\section{Conclusion}

The present study, for the first time, demonstrated that GABA agonists in minimal dose could decrease tolerance in the long-term administration of morphine, and GABA operates these mechanisms through reduction of NO augmented by activation of NMDA receptors. NMDA receptor and NO play a crucial role in hyperalgesia in morphine tolerance models, but GABA agonists could decrease NO and hyperalgesia and can be administrated with morphine in the long-term use to prevent tolerance for antinociceptive effect of morphine.

\section{References}

Backonja, M., Glanzman, R.L., 2003. Gabapentin dosing for neuropathic pain: Evidence from randomized, placebocontrolled clinical trials. Clin. Therapeut., 25, 81-104.

Bekhit, M.H., 2010. Opioid-induced hyperalgesia and tolerance. Am. J. Therapeut., 17, 498-510.

Bobeck, E.N., Chen, Q., M organ, M.M., Ingram, S.L., 2014. Contribution of adenylyl cyclase modulation of pre-and postsynaptic GABA neurotransmission to morphine antinociception and tolerance. Neuropsychopharmacol., $39,2142$.

Bonci, A., Williams, J.T., 1997. Increased probability of GABA release during withdrawal from morphine. J. Neurosci., 17, 796-803. 
Shima M ehrabadi and Seyed Shahabeddin Sadr / International Journal of Advanced Biological and Biomedical Research (2018) 7(1) 129-134

Dumont, H., Guntz, E., Sosnowski, M., Talla, G., Roman, A., Segers, B., 2007. Opioid-induced hyperalgesia. Eur. J. Anaesthesiol., 24, 205-207.

Fraser, G.L., Gaudreau, G.A., Clarke, P., Menard, D.P., Perkins, M.N., 2000. Antihyperalgesic effects of $\delta$ opioid agonists in a rat model of chronic inflammation. Br. J. Pharmacol., 129, 1668-1672.

Gilron, I., Bailey, J.M., Tu, D., Holden, R.R., Weaver, D.F., Houlden, R.L., 2005. Morphine, gabapentin, or their combination for neuropathic pain. New Engl. J. M ed., 352, 1324-1334.

Hill, R., Lyndon, A., Withey, S., Roberts, J., Kershaw, Y., Maclachlan, J., Lingford-Hughes, A., Kelly, E., Bailey, C., Hickman, M., 2016. Ethanol reversal of tolerance to the respiratory depressant effects of morphine. Neuropsychopharmacol., 41, 762.

Ho, K., Loh, H.H., Way, E.L., 1976. Pharmacological manipulation of gamma-aminobutyric acid (GABA) in morphine analgesia, tolerance and physical dependence. Life Sci., 18, 1111-1123.

Hosseini, M., Karami, Z, Janzadenh, A., Jameie, S.B., Haji Mashhadi, Z, Yousefifard, M., Nasirinezhad, F., 2014. The effect of intrathecal administration of muscimol on modulation of neuropathic pain symptoms resulting from spinal cord injury; an experimental study. Emerg., 2, 151-157.

Hunt, S.P., M antyh, P.W., 2001. The molecular dynamics of pain control. Nat. Rev. Neurosci., 2, 83.

Hwang, J.H., Yaksh, T.L., 1997. The effect of spinal GABA receptor agonists on tactile allodynia in a surgicallyinduced neuropathic pain model in the rat. Pain, 70, 15-22.

Idänpään-Heikkilä, J..., Guilbaud, G., 1999. Pharmacological studies on a rat model of trigeminal neuropathic pain: Baclofen, but not carbamazepine, morphine or tricyclic antidepressants, attenuates the allodynia-like behaviour. Pain, 79, 281-290.

Knott, A.B., Bossy-Wetzel, E., 2009. Nitric oxide in health and disease of the nervous system. Antioxidants \& Redox Signaling, 11, 541-553.

Kolesnikov, Y.A., Pick, C.G., Ciszewska, G., Pasternak, G.W., 1993. Blockade of tolerance to morphine but not to kappa opioids by a nitric oxide synthase inhibitor. Proceedings of the National Academy of Sciences, 90, 51625166.

Li, X., Clark, J.D., 2001. Spinal cord nitric oxide synthase and heme oxygenase limit morphine induced analgesia. Mol. Brain Res., 95, 96-102.

Ma, J., Pan, Z.Z., 2006. Contribution of brainstem GABAA synaptic transmission to morphine analgesic tolerance. Pain, 122, 163-173.

Malmberg, A.B., Yaksh, T.L., 1993. Spinal nitric oxide synthesis inhibition blocks NMDA-induced thermal hyperalgesia and produces antinociception in the formalin test in rats. Pain, 54, 291-300.

Manning, B.H., Mao, J., Frenk, H., Price, D.D., Mayer, D.J., 1996. Continuous co-administration of dextromethorphan or M K-801 with morphine: Attenuation of morphine dependence and naloxone-reversible attenuation of morphine tolerance. Pain, 67, 79-88.

Meller, S., Pechman, P., Gebhart, G., M aves, T., 1992. Nitric oxide mediates the thermal hyperalgesia produced in a model of neuropathic pain in the rat. Neurosci., 50, 7-10.

Quintero, L., Cardenas, R., Suarez-Roca, H., 2011. Stress-induced hyperalgesia is associated with a reduced and delayed GABA inhibitory control that enhances post-synaptic NM DA receptor activation in the spinal cord. Pain, 152, 1909-1922.

Ratajczak-Wrona, W., Jablonska, E., Antonowicz, B., Dziemianczyk, D., Grabowska, S.Z, 2013. Levels of biological markers of nitric oxide in serum of patients with squamous cell carcinoma of the oral cavity. Int. J. Oral Sci., 5, 141.

Renfrey, S., Downton, C., Featherstone, J., 2003. The painful reality. Nature Publishing Group.

Rudd, R.A., Aleshire, N., Zbbell, J.E., M atthew Gladden, R., 2016. Increases in drug and opioid overdose deathsUnited States, 2000-2014. Am. J. Transplant., 16, 1323-1327.

Schmidtko, A., Gao, W., König, P., Heine, S., M otterlini, R., Ruth, P., Schlossmann, J., Koesling, D., Niederberger, E., Tegeder, I., 2008. CGM P produced by NO-sensitive guanylyl cyclase essentially contributes to inflammatory and neuropathic pain by using targets different from CGM P-dependent protein kinase I. J. Neurosci., 28, 8568-8576.

Sivam, S., Ho, I., 1983. GABAergic drugs, morphine and morphine tolerance: A study in relation to nociception and gastrointestinal transit in mice. Neuropharmacol., 22, 767-774.

Snyder, S.H., 1992. Nitric oxide: first in a new class of neurotransmitters? Sci., 257, 494-496. 
Shima M ehrabadi and Seyed Shahabeddin Sadr / International Journal of Advanced Biological and Biomedical Research (2018) 7(1) 129-134

Takahashi, M., Kaneto, H., 1995. Role of GABAergic systems in the development of morphine tolerance in formalintreated mice. Jap. J. Pharmacol., 68, 207-211.

Tiseo, P.J., Inturrisi, C.E., 1993. Attenuation and reversal of morphine tolerance by the competitive N-methyl-Daspartate receptor antagonist, LY274614. J. Pharmacol. Exp. Therapeut., 264, 1090-1096.

Velayudhan, A., Bellingham, G., Morley-Forster, P., 2014. Opioid-induced hyperalgesia. Cont. Educ. Anaesth. Crit. Care Pain, 14, 125-129.

Zanfirescu, A., Cristea, A.N., Nitulescu, G.M., Velescu, B.S., Gradinaru, D., 2017. Chronic monosodium glutamate administration induced hyperalgesia in mice. Nutr., 10, 1.

How to cite this article: Mehrabadi, S., Sadr, S.S., 2018. GABA Agonists could Decrease Hyperalgesia and NO Serum Level in Morphine Tolerance Model. International Journal of Advanced Biological and Biomedical Research, 6(2), 129-134. 